\title{
Características del turismo entre los pueblos indígenas
}

\author{
Roger Martínez Castillo*
}

Recibido: Marzo 2012 • Aceptado: Mayo 2012

\section{RESUMEN}

El turismo es una actividad humana relativamente reciente en su forma masiva que plantea nuevos sentidos y significados a los espacios, territorios y lugares naturales y culturales. Al respecto, surgen los espacios turísticos en los territorios indígenas, que son redescubiertos. De esta manera, el turismo se presenta como una actividad que puede resolver algunos problemas de desarrollo entre los pueblos indígenas, al integrarlos a la dinámica mercantil. Sin embargo, implica riesgos de aculturación y transculturación para los pueblos locales mismos, sin ignorar los posibles riesgos de impactos físicos y ambientales. Aquí sobresale la importancia del control o regulación local sobre el proceso del desarrollo de las actividades turísticas inducidas externamente.

Palabras clave: turismo, indígena, cultura, ambiente y desarrollo.

\section{ABSTRACT}

Tourism, in its massive way, is a relatively recent human activity that gives new sense and meaning to spaces, territories and places. In this regard, tourist spaces surge in indigenous territories, which are rediscovered. Tourism is presented as an activity that can solve some development problems within the indigenous communities. However, tourism implies acculturation and transculturation risks for the local people, in addition to the physical and environmental impact risks. It is of great importance here the local control over the development process of tourist activities.

Key words: Tourism, indigenous, culture, environment and development.

\section{Introducción}

Todavía hoy muchos pueblos indígenas y muchas comunidades rurales poseen un conocimiento profundo y detallado de los ecosistemas y de los bienes naturales y culturales con los que se encuentran en constante contacto. Un ejemplo de estos conocimientos

\footnotetext{
* Doctor Catedrático Universidad de Costa Rica. E-mail: yarustio@hotmail.com
} 
tradicionales es la utilización y el manejo de la flora y fauna, como el bosque y otros sistemas agrícolas y agroforestales, y de los bienes silvestres en general. Además, reflejan conocimientos, habilidades y técnicas culturales apropiadas al manejo ecológico del entorno natural.

Diversas investigaciones en ecología confirman lo que los pueblos indígenas del mundo han sabido siempre: que la actividad humana a lo largo de la historia ha sido un motor para el desarrollo de la diversidad biológica que hemos heredado (Toledo, 1995). Los pueblos indígenas son portadores de un acervo cultural extremadamente rico, así como de un enorme conocimiento y respeto de la biodiversidad de las selvas y demás ecosistemas y, por eso, se han constituido en protagonistas para el desarrollo de tecnologías de punta.

Los pueblos indígenas han heredado la sabiduría del ecosistema (Madre Selva), transmitida de generación en generación. Ellos saben cómo, cuándo y dónde se puede cazar y pescar; conocen las reglas, las dietas, las prevenciones y precauciones que se deben tener al realizar estas actividades. Saben leer las estrellas, el tiempo, los cambios del clima para la siembra y cosecha; saben cuándo la tierra necesita rotar o descansar.

Su desarrollo está orientado a apropiarse del ecosistema con un mínimo de costos energéticos. La relación de los pueblos indígenas con la flora, fauna, suelo, agua, ocurre bajo la premisa de que se trata de partes integrantes de un todo mayor, donde ellos mismos están incluidos. Se trata de reproducir el ciclo natural en el cultivo agrícola.

Los pueblos indígenas parten del supuesto de que "la tierra no pertenece al hombre, el hombre pertenece a la tierra. Somos parte de la tierra" (Gran Jefe Seattle, 1884). Por eso, no la consideran como un simple recurso económico, sino como una necesidad para la vida; de ahí el interés en preservarla, conservarla y cuidarla.

La clave de la comprensión está en el proceso de apropiación/producción y consumo. Como sujetos sociales que realizan procedimientos intelectuales (conocimiento, percepción y creencias), toman decisiones y ejecutan operaciones prácticas durante su relación con la naturaleza. Esto permite superar la práctica recurrente y equivocada entre los investigadores convencionales, de situar fuera del contexto los componentes intelectuales y prácticos, que en realidad aparecen formando parte de un solo sistema: el proceso de producción local.

Los pueblos indígenas son quienes han desarrollado y poseen estos conocimientos, transmitidos de generación en generación, acerca de la biodiversidad agrícola 
y silvestre. Gracias a ellos, la biodiversidad se ha podido utilizar y conservar. De aquí la importancia e interés de que se pueda analizar un proceso de desarrollo del sector servicios, como lo es el turismo entre los pueblos indígenas hacia afuera.

Sin embargo, el proceso de subordinación de la cultura indígena por parte de la concepción moderna convencional, está provocando su degradación interna. Lo más grave de todo es el desconocimiento y no reconocimiento que tienen los pueblos indígenas sobre su territorio, su ecosistema y conocimientos tradicionales.

\section{Cultura y ambiente}

Cultura es el conjunto de estrategias y comportamientos institucionalizados que la práctica social e histórica de un pueblo ha consolidado como herramienta para asegurar su supervivencia y reproducción, en una relación mutua de transformación con el ambiente.

Pero también la cultura es entendida como un proceso de producción y transmisión de sentidos que constituyen el mundo simbólico de las personas y las sociedades. En este sentido, es diálogo e intercambio de ideas que permiten apreciar, del otro, sus valores y tradiciones. Una cultura no puede pervivir en el aislamiento, porque se agota y perece.
Por eso, se debe conceptuar y caracterizar la cultura desde una perspectiva de las creencias y valores de los ciudadanos, de sus formas de vida, de trabajo, de organización, de sus hábitos cotidianos, de sus formas de amar y morir, de aquello que se ha compartido y cuya práctica ha proporcionado un pasado común y una historia diversa en un grupo humano.

Los impactos que el uso y manejo de los bienes naturales tienen sobre los ecosistemas están íntimamente ligados a las prácticas agrícolas, pecuarias, forestales, pesqueras y extractivas desde una específica racionalidad ecológico-productiva. El desarrollo rural, que es el conjunto de dinámicas del universo agrario, se logra comprender cabalmente mediante el reconocimiento de estas fuerzas o racionalidades que, como producto de la historia se enfrentan, anulan, combinan o se mantienen separadas y distantes (Toledo, 1995). El acto material por el que los seres humanos se articulan con la naturaleza, es un fenómeno que solo puede ser analizado desde una perspectiva integradora, como la ecología y economía (Toledo, 1989; Martínez Alier, 1999).

La cultura humana es como una cédula de identidad que contiene códigos culturales heredados por una colectividad histórica, en el tiempo y espacio. La cultura refleja una estrategia de supervivencia 
vinculada con el uso y manejo racional del ecosistema, mediante formas tradicionales de organización de la sociedad y su ambiente. Cultura son todas aquellas expresiones fenoménicas, materiales y espirituales que resultan y que son base de la relación dialéctica entre las personas y su entorno biofísico, para garantizar su reproducción como pueblo (Borge, 2000).

La estructura cultural, como el lenguaje, los conocimientos y formas de transmitirlos, la manera de ordenar los espacios y ocuparlos, las manifestaciones rituales, signos, símbolos y las costumbres, no son hechos aislados de supervivencias populares; estos reflejan un sistema categorial, las condiciones y relaciones de la vida práctica (Iturra, 1993).

\section{El turismo y la construcción del espacio}

El turismo es una actividad humana relativamente reciente en su forma masiva que dota de nuevos sentidos y significados a espacios, territorios y lugares. Es una manera de producción del espacio realizada a través de sus procesos de visitación externa. El turismo, en su relación con la globalización, ha contribuido de forma decisiva a la redefinición y el cambio generados en muchos territorios durante los últimos 50 años (Vera, 1997), pero también puede ser pensado como una técnica para la producción espacial de la localidad (Appadurai, 1995), donde determinados elementos del territorio son convertidos en emblemas identitarios y productos culturales "para el turista ver”. Según Appadurai (2004), el turismo es una actividad de flujos de personas, información, ideas, productos y capital.

Segun Urry (1995), en esta época posmoderna, muchos sitios se han convertido en espacios de consumo, consumidos en su vertiente visual experimental.

Hoy asistimos a un cambio de modelo turístico, pues pasamos de un modelo de turismo fordista a otro posfordista.

El modelo turístico fordista (Vera, 1997) se caracterizaba por la especialización sectorial a partir del uso de recursos naturales como la playa o la montaña y por una oferta homogénea en la cual el destinatario era visto como una masa, sin diversidad ni singularidad. Lo que interesaba era maximizar el número de visitantes, incluso a costa de degradar el ambiente natural y sociocultural. Este modelo concentraba la oferta turística en términos territoriales, lo que se puede asociar a una tensión sociocultural entre anfitriones y visitantes (pensados como intrusos).

Frente al modelo fordista, el modelo turístico posfordista 
(Donaire, 1998) nace por la crisis, la homogenización y uniformización de los destinos turísticos. Por ello, la oferta se empieza a singularizar y diferenciar, creándose productos específicos para segmentos específicos de turistas. Los turistas de más edad pueden tener más interés en las palabras, mientras que los jóvenes en imágenes e información virtual; unos pueden querer primero comer y luego ver el sitio de interés cultural; unos quieren ver el sitio siguiendo las rutas turísticas convencionales, en tanto que otros quieren "descubrirlo" o perderse en él. En este modelo posfordista, se entiende mejor la valoración del patrimonio cultural, la festivalización de eventos, la nueva ética turístico-ecológica, el turismo de trabajo (ej.: turismo de congresos, científicos y otros).

La nueva demanda convierte cualquier espacio en un potencial espacio turístico, y en cualquier tema en "turistizable" (Donaire, 1998). Por lo tanto, en este modelo posfordista se puede entender mejor la demanda de turismo étnico, cultural.

El turismo étnico (Oakes, 2000) en América Latina tiene como objeto de producción y consumo, lo que Darcy Ribeiro (1977) define como "pueblos testigos", es decir, los pueblos indígenas con los cuales habían contactado los europeos y que han ido recreando su identidad. Frente a ellos están los "pueblos nuevos", resultado de la mezcla y la interculturalidad, y los "pueblos transplantados" o pueblos inmigrantes europeos tardíos. Por adaptación al turismo, estos "pueblos testigos" recrean su identidad y su espacio por medio de la auto-presentación a otros grupos humanos y de la conversión de su espacio en una especie de zoológico humano indigenizado.

Este turismo convierte sitios indígenas en localidades turísticas, que abren una ventana para ver su identidad. De esta forma, se convierte en una estrategia de re-invención de la identidad, que representa un capital potencialmente activable. Al mismo tiempo, contribuye a la creación de nuevos sentidos del lugar, en un tiempo de recolonización global-local. Así, la etnicidad reconstruida para los turistas mercantiliza la cultura y transfiere las localidades para el mercado global, aunque sea a costa de perder privacidad y experimentar un sentimiento de invasión y amenaza (MacCannell, 1992).

El turista piensa que con el dinero se puede llegar a visitar todo, pero, como reacción, algunos habitantes locales sacralizan espacios y crean límites de acceso para aquel; aunque algunos pueblos indígenas defienden el "espacio privado" frente al turismo y los turistas (Boissevain, 2005). 
Para eso, intentan mostrar al turista solo los "espacios colectivos". De esta manera, el turista promueve el autoconocimiento, el orgullo, la solidaridad y la autoconfianza de los residentes locales frente a los visitantes.

Por un lado, el turismo puede estimular la identidad étnica y local. Y, por otro lado, implica un riesgo de pérdida de la privacidad y puede favorecer el "intrusismo", lo que transforma a dichos pueblos en museos vivientes degradantes, abiertos con su cultura en proceso de "congelamiento", algo similar a lo que se planteaba Lévi-Strauss (1964) con el "buen salvaje".

Para Boissevain (2005), existen seis estrategias de reacción de las comunidades tradicionales frente al turismo:

1. "Resistencia encubierta", es decir, utilizar imágenes estereotipadas que infravaloran, frenan y engañan a los turistas. Esta estrategia ayuda a que las personas que están en una posición subordinada tengan respeto propio.

2. Esconder aspectos de la cultura local a los turistas, para que no incomoden.

3. Rechazar y cerrarse en la privacidad, por ejemplo, cambiando una actividad que atraía turistas para otra fecha o sitio. Es una forma de limitar la participación de estos.

4. El ritual: elabora formas de celebrar la identidad comunitaria sin turistas. Es una respuesta a las amenazas que el turismo lanza a la comunidad local.

5. La protesta organizada.

6. Y la agresión violenta como expresión de hostilidad abierta.

Sea cual sea la reacción local frente a la visitación, el turismo acaba por re-significar el espacio y los sentidos del lugar introduciendo nuevos actores sociales y reconvirtiendo viejos escenarios en lugares turísticos (Cardería da Silva, 2004) o palcos de la experiencia ritual turística.

\section{Impacto sociocultural del turismo}

El turismo no es el único ni el más importante agente de transformación (degradación) social y cultural (Mathieson y Wall, 1990; Smith, 1992); hay otros como los medios de comunicación (mediáticos), las emigraciones e inmigraciones, la educación escolar convencional y la penetración agro-productiva del monocultivo.

Además, el turismo como agente de cambio social y cultural no tiene que ser siempre considerado como algo solo negativo o perjudicial. Este no siempre destruye, ni en 
todos sus aspectos, las tradiciones indígenas, sino que las re-inventa. Del mismo modo, no solo afecta a los pueblos hospederos de turistas, sino también a los propios turistas. Estos cambios no son lineales y no son de afuera para adentro, sino que obedecen a complejas relaciones dialécticas en que los pueblos indígenas no son pasivos, sino activos agentes de debate con el turismo (Pereiro e Inawinapi, 2007).

Para empezar, es necesario preguntarse: ¿cuál es el precio que pagan los pueblos indígenas por el turismo?, ¿cuáles son los beneficios reales?, ¿son los intereses de tales pueblos respetados y tenidos en cuenta? La situación de muchos pueblos indígenas y su relación con la actividad turística no ha sido ni es fácil. Los ejemplos en algunas zonas del mundo muestran que muchos son expulsados de sus territorios, generándose una degradación de la vida social y cultural. El resultado ha sido evidente: la migración a los centros urbanos; la comercialización de la cultura como una mercancía más; la contaminación de los ecosistemas y la amenaza de la biodiversidad, debido a la invasión sin control de visitantes; la producción de desechos o basura resultado de la actividad turística; el abandono de actividades tradicionales como la agricultura, pesca y caza, en nombre del turismo y otros.
Es lo que se conoce como la pérdida de la construcción (o desestructuración) indígena, mediante procesos convencionales que los llevan a convertirse en simples pueblos rurales, pero carentes del carácter tradicional.

El turismo posibilita viajar y participar de culturas diferentes de las del turista. Reestructura la sociedad de acogida y genera impactos socioculturales que provocan efectos en los habitantes locales, en los visitantes y en su sociedad de origen.

Agustín Santana (1997) distingue entre impacto social e impacto cultural. El impacto social del turismo está asociado con los cambios en la estructura social de las comunidades receptoras, en su calidad de vida, en las relaciones sociales, de adaptación y pérdida de autonomía. Por su parte, el impacto cultural categoriza cambios más graduales y procesuales, que van ocurriendo a medida que el turismo se desarrolla, tales como la aculturación turística y los cambios en las normas, en la cultura material y los patrones culturales.

La literatura antropológica es generalmente negativa en cuanto a los impactos del turismo, pues enfatiza en la intromisión de un sistema cultural externo y fuerte en otro más débil, la destrucción de aspectos culturales y la homogenización cultural. Sin embargo, esta 
visión se ve matizada últimamente (Boissevain, 2005), debido a nuevos descubrimientos sobre la complejidad del turismo y sus impactos.

Algunos ejemplos de ello se manifiestan en (Pereiro e Inawinapi, 2007):

1. El primer y más evidente impacto sociocultural del turismo consiste en el aumento de las relaciones interculturales y sus intercambios. El turismo permite conocer gente de todo el mundo.

2. Aumento de ingresos económicos familiares y locales, de forma desigual.

3. La actividad económica central pasa a ser la de servicios: venta de artesanía y transformación de sus significados.

4. Abandono de otras actividades económicas básicas tradicionales.

5. El turismo ha afectado las estructuras organizativas de los pueblos, generando cambios en la estructura políticoadministrativas locales y rivalidades interlocales por la distribución de los beneficios del turismo.

6. Nuevos productos $\mathrm{v}$ modelos de consumo importados. El consumo ha sido muy influido por el turismo.

7. Nuevas oportunidades de empleo y mejora en ingresos.
8. "Estereotipación" de la cultura local ante los visitantes.

\section{Biopiratería "científica"}

El tema del acceso a los recursos genéticos y bioquímicos, así como la distribución justa y equitativa de sus beneficios derivados, va de la mano con el tema de bioprospección o biopiratería.

La mal llamada bioprospección, que no es otra cosa que la biopiratería, es la exploración de la diversidad biológica y del conocimiento tradicional asociado, para facilitar la selección y extracción de recursos genéticos y bioquímicos que puedan resultar en productos comerciales, sin tomar en cuenta los intereses y necesidades de los pueblos indígenas. Además, son los procesos de extracción legal/ilegal de recursos genéticos y biológicos que se han producido milenariamente y todavía se llevan a cabo, sin la aprobación de las comunidades propietarias legítimas de esta información y que conducen al monopolio sobre la propiedad intelectual por parte de las transnacionales farmacéuticas.

Uno de sus mejores ejemplos es la biopiratería, nombre real del saqueo o práctica mediante la cual investigadores o empresas transnacionales usan ilegalmente la biodiversidad de países en desarrollo y los conocimientos colectivos de 
pueblos indígenas o campesinos, para patentar productos y servicios que se explotan sin la autorización de sus creadores.

La biopiratería es una práctica mediante la cual investigadores o empresas utilizan (i)legalmente la biodiversidad de países en desarrollo y los conocimientos colectivos de pueblos indígenas o campesinos, para elaborar productos y brindar servicios sin la autorización de sus creadores o innovadores y así, comercializar los conocimientos tradicionales indígenas, sin su consentimiento o aceptación (Martínez, 2010).

Estos conocimientos sobre el uso de la biodiversidad e incluso las propias especies biológicas han sido patentados, por diversas transnacionales, como propiedad industrial. La biopiratería es la privatización de los recursos biológicos y su conocimiento asociado mediante sistemas de propiedad intelectual. En esta las corporaciones farmacéuticas, alimentarias, cosméticas, dietéticas, biotecnológicas, de investigación de materiales biológicos de aplicación industrial, extractivas o de explotación intensiva de bienes naturales; así como las industrias turísticas, de transferencia tecnológica, de investigación académica, jurídicas, médicas, geográficas, de la información y del entretenimiento y otras, pretenden apropiarse de la biodiversidad y del conocimiento indígena vinculado. Además, los patrones de producción y consumo de los países industrializados, causan destrucción y violación de derechos fundamentales y colectivos en los países del Sur.

Las industrias con necesidad de zonas de biodiversidad, como la farmacéutica, tienen un futuro prometedor a cambio de una insignificante aportación a los indígenas por servicios de información de su ancestral sabiduría. Los mercados verdes generan ganancias a través de estrategias como las del comercio justo, que ponen en los mercados occidentales una variedad de productos exóticos. La comercialización de las tradiciones mediante los denominados eco y etno-turismo se ha insertado en las comunidades. Por eso, el intento de organismos como el BM o el FMI, que ven lo indígena como potencial económico en un marco de desarrollo sostenible impuesto siempre desde fuera. Comparten la cosificación de su territorio y tradiciones, al percibirlos sólo con parámetros económico-productivos (Ulloa, 2004).

A diferencia del funcionamiento de la lógica moderna (mercadocéntrica), que se basa en la exclusión de los contrarios y en el dominio técnico-instrumental de la naturaleza y la sociedad misma, existe en los pueblos indígenas una tendencia permanente hacia la 
búsqueda del principio de respeto por el ciclo de regeneración del ecosistema entre los seres humanos y entre estos y el mundo circundante.

\section{Control local del turismo}

La explotación de toda actividad turística y sus modalidades en algún territorio indígena debe reservarse y estar bajo control de los propios indígenas, pues de esta manera podrán ejercer un control sobre los impactos del turismo en sus pueblos (Tourism Concern, 1998).

Lo correcto es que este proceso de control y regulación de las propias comunidades locales, evite algún impacto negativo sobre su contexto sociocultural y natural, que permita comprender mejor el turismo como agente y proceso de cambios. Estos cambios no son lineales y no son de afuera para dentro, sino que obedecen a complejas relaciones dialécticas en las cuales los indígenas no son pasivos, sino sujetos activos de debate con el turismo.

"La presencia de elementos culturales de origen externo, no indica por sí misma debilitamiento ni pérdida de autenticidad de las culturas locales. El problema está en quienes ejercen el control sobre esos rasgos. Es decir, es necesario determinar si la matriz cultural es propia o ajena" (Bonfil, 1982). Para que un pueblo tenga el control social y cultural para construir su futuro, debe aprovechar las enseñanzas de su experiencia histórica, los recursos reales y potenciales propios de su cultura, valores y aspiraciones.

CUADRO 1

Toma de decisión

\begin{tabular}{lcc}
$\begin{array}{c}\text { RECURSOS } \\
\text { (control) }\end{array}$ & \multicolumn{2}{c}{ DECISIONES } \\
Interno & $\begin{array}{c}\text { Cultura } \\
\text { autónoma }\end{array}$ & $\begin{array}{c}\text { Cultura } \\
\text { enajenada }\end{array}$ \\
Externo & $\begin{array}{c}\text { Cultura } \\
\text { apropiada }\end{array}$ & $\begin{array}{c}\text { Cultura } \\
\text { impuesta }\end{array}$ \\
\hline
\end{tabular}

Bonfil, 1982.

El control cultural se entiende como la capacidad social de decisión local sobre los ecosistemas; sobre todos aquellos componentes de una cultura que deben ponerse en juego para identificar las necesidades, problemas y aspiraciones de la propia sociedad e intentar satisfacerlas, resolverlas y cumplirlas.

El control cultural del turismo, como fenómeno social, es un proceso, y no una situación estática; se halla dentro de un momento histórico, pero a partir de una dimensión política (capacidad de decisión interna), donde el desarrollo endógeno pretende mantener la capacidad de decisión del propio grupo social y cultural, tanto sobre sus recursos propios, como sobre los recursos ajenos, de los que se apropia. El problema queda a nivel político, 
pues es un asunto de capacidad autónoma de decisión, que plantea dos aspectos (Bonfil, 1982):

1. Aumenta la capacidad de decisión sobre los recursos (tierra, conocimiento, historia, tecnología), fortaleciendo las formas de organización, que permiten el control cultural local; esto incide en el enriquecimiento de la cultura autónoma.

2. Acrecienta la disponibilidad de recursos externos bajo control local: nuevas tecnologías, habilidades y conocimientos, formas de organización productiva y administrativa.

El control puede ser total o parcial, directo o indirecto, absoluto o relativo, en referencia a cualquier acción cultural política. Lo importante es que las relaciones entre estos ámbitos de la cultura y lo social sean relaciones de poder. El incremento actual de la cultura impuesta externamente y enajenada en muchos pueblos rurales, no es el resultado de una confrontación entre elementos culturales, como se pretende hacer aparecer, sino la imposición del modelo convencional dominante histórico, que está en proceso de decadencia, ante la imposibilidad de resolver asuntos tan delicados como la pobreza, la exclusión y la contaminación ambiental misma a escala planetaria.
Se abandonan los cultivos tradicionales y la autonomía alimentaria (cultura autónoma, donde ejercen decisiones propias, basadas en conocimientos, habilidades tecnológicas, formas de organización, hábitos de trabajo y consumo, creencias y valores tradicionales) por cultivos comerciales, que implican una cultura impuesta, donde los recursos (semillas, créditos, tecnología) no están bajo el control de la comunidad.

El control de los ecosistemas y el fortalecimiento de la cultura autónoma pasan por la restitución y garantía de los territorios históricos, culturales. Hablar de reconocimiento político, es hablar de autogestión. La capacidad para la autogestión está relacionada, con formas propias de organización social que funcionen dentro de la comunidad local.

El desarrollo de formas de organización propias, tradicionales, no significa rechazar la innovación, ni privilegiar las formas tradicionales, como las únicas válidas o permanentes. Para ello, deben surgir elementos, a partir de su propia cultura, en el conocimiento de su verdadera historia, valorando sus propios recursos y adquiriendo conocimientos de los que estos pueblos puedan apropiarse. Así, el desarrollo endógeno sería la capacidad autónoma de una sociedad culturalmente diferenciada para guiar 
su propio destino. Esta capacidad autónoma solo puede alcanzarse si estas sociedades locales constituyen unidades políticas con posibilidad real de autodeterminación, de gobernarse, de tomar sus propias decisiones. La autodeterminación implica una forma de organización del poder, significa la constitución del grupo local como unidad político-administrativa, con autoridad sobre su territorio y con capacidades de decisión en todos los ámbitos de su desarrollo interno.

El desarrollo debe ser un asunto interno de cada pueblo y comunidad. La función del Estado no consiste en definir este ni llevarlo a cabo, sino en contribuir a crear las condiciones que lo hagan posible. Para ello, se debe transformar radicalmente el contexto social, económico, político e ideológico de la sociedad nacional, que impide el florecimiento y desarrollo de los pueblos locales (Mires, 1990).

En la actualidad, algunas voces defienden la potenciación del modelo eco-turístico en las áreas indígenas: ríos, selvas, rituales, danzas y otros.

Algunos de los puntos más centrales de la comunicación son los siguientes:

1. La propuesta de descripción e interpretación de un modelo de desarrollo turístico controlado y definido políticamente por los propios pueblos indígenas.

2. Los aspectos metodológicos: trabajo de campo en equipo, observación intensiva y extensiva por todo el territorio indígena.

3. La co-investigación antropológica con los propios indígenas.

4. Una etnografía reflexiva sobre el sistema turístico para cambiar los sistemas socioculturales.

5. La reflexión crítica sobre los impactos del sistema turístico, su resistencia y su alerta para la creación de modelos de turismo alternativos.

\section{Resumen}

La historia del turismo en algunos pueblos indígenas es una historia de luchas y resistencia. Esta lucha se ve en la toma del control del proceso de desarrollo turístico, diciendo no al turismo de masas y sí al desarrollo de un turismo más artesano, pausado.

El turismo ha posibilitado mayor visibilidad nacional e internacional para algunos pueblos indígenas, pero sus impactos han generado efectos sobre el ambiente y las estructuras sociales que están redefiniendo su espacio como un espacio local y posicionando a los indígenas y sus territorios en el mercado turístico global. Los 
efectos considerados negativos intentan ser paliados y controlados por los propios indígenas, algo que redefinirá nuevamente los sentidos del lugar y que presentará este con un nuevo traje.

El turismo representa una historia de confrontaciones, desencuentros y conflictos entre los pueblos indígenas y no-indígenas, pero también entre los indígenas mismos. Implica riesgos de aculturación y transculturación para los propios pueblos locales, sin ignorar los relacionados con impactos físicos y ambientales. Desde el punto de vista económico, representa un riesgo de dependencia económica, pero al mismo tiempo una oportunidad y una estrategia de reproducción para los pueblos indígenas mismos.

El turismo se ha presentado como una actividad que puede resolver algunos problemas de desarrollo entre los pueblos indígenas. Sin embargo, se ha convertido en una estrategia para redituarse en la compleja trama de la interculturalidad contemporánea. De esta forma, lo considerado "tradicional", "indígena" o "étnico" es resignificado, reconceptualizado y refuncionalizado desde lo moderno para responder a las necesidades económicas, culturales, políticas e ideológicas de las sociedades occidentales, en las actuales relaciones local-global.

\section{Bibliografía}

Appadurai, A. (1995). The Production of Locality. Ardon, Richard (dir.). Counterworks Managing the Diversity of Knowledge, Londres: Routledge.

Appadurai, A. (2004). Dimensiones culturales de la globalización. Barcelona: Teorema.

Bonfil Batalla, G. (1982). Utopía y revolución. El pensamiento político contemporáneo de los indios en América Latina. México: Nueva Imagen.

Borge, C. (2000). La estrategia de cambio cultural en los bribris de Talamanca. Tesis de Maestría en Antropología, Universidad de Costa Rica, San José.

Boissevain, J. (2005). Rituales ocultos. Protegiendo la cultura de la mirada turística. Pasos. Revista de Turismo y Patrimonio Cultural. Vol. 3, núm. 2, 217-228.

Cardería da Silva, M. (2004). Outros Tropicos. Novos destinos turisiticos. Novos terenos da antropología. Lisboa: Livros Horizonte.

Donaire, J.A. (1998). La geografía del turismo después del fordismo: turistas en las fábricas, turistas en los centros comerciales. Sociedade e Territorio, núm. 20, 55-68.

Iturra, R. (1993). Letrados y campesinos: el método experimental en antropología económica. Madrid: La Piqueta.

Lévi-Strauss, C. (1964). El pensamiento salvaje. México: Fondo de Cultura Económica.

MacCannell, D. (1992). Empty Meeting Grounds. New York: Routledge and Kegan Paul.

Martínez Alier, J. (1999). Introducción a la Economía Ecológica. Madrid: Rubes. 
Martínez, R. (2005). Fundamentos culturales, sociales y económicos de la agroecología. Revista Ciencias Sociales, núm. 13-14, IIS, UCR.

Martínez, R. (2010). Biopiratería y pueblos indígenas: crítica y realidad. Revista Hoja Filosófica, núm. 23, octubre, IDELA, UNA.

Mathieson, A. y Wall, G. (1990). Turismo. Repercusiones económicas, físicas y sociales. México: Trillas.

Mires, F. (1990). El discurso de la naturaleza. Ecología y política en América Latina. San José: Editorial Departamento Ecuménico de Investigaciones.

Mires, F. (1991). Discurso de la Indianidad: la cuestión indígena en América Latina. San José: Editorial Departamento Ecuménico de Investigaciones.

Oakes, T. (2000). Ethnic Tourism. Encyclopedia of tourism, 204-206, London: Belhaven Press.

Pereiro, G. e Inawinapi, C. (2007). Los impactos del turismo en Kuna Yala: turismo y cultura entre los Kunas de Panamá. Portugal, Universidade Transmonte de Alto Douro: Areces.

Ribeiro, D. (1977). La universidad latinoamericana y el desarrollo social. Ribeiro, D. (org.): Elites y desarrollo en América Latina. Buenos Aires: Paidós, 415-449.

Santana, A. (1997). Antropología y turismo. Barcelona: Ariel.
Smith, V. (1992). Introducción. Smith, V. (org.). Anfitriones e invitados. Antropología del turismo. Madrid: Endimión, 15-41.

Toledo, V. M. (1989). Naturaleza, producción, cultura. Ensayos de ecología políti$\boldsymbol{c a}$. México: Universidad Veracruzana.

Toledo, V. M. (1994). Las culturas indígenas frente al neoliberalismo y la globalización. (4-5 de agosto de 1994). Seminario de Estudios de la Cultura de la Secretaría de Educación Pública de México.

Toledo, V. M. (1995). Campesinidad, agroindustrialidad, sostenibilidad: fundamentos ecológicos e históricos del desarrollo rural. Cuadernos de Trabajo: 1-45, Grupo Interamericano para el Desarrollo Sostenible de la Agricultura y de los Recursos Naturales. México.

Toledo, V. M. (2003). Ecología, espiritualidad y conocimiento-de la sociedad del riesgo a la sociedad sustentable. Puebla, México: Universidad Iberoamericana.

Tourism Concern (ed.) (1998). Controlling Tourism Throgh Status: Does it Works? Tourism Concern, núm. 29, 11-13.

Urry, J. (1995). Consuming Places. Londres: Routledge.

Ulloa, A. (2004). La construcción del nativo ecológico. Bogotá: ICANH.

Vera, F. (coord.) (1997). Análisis territorial del turismo. Barcelona: Ariel. 